\title{
Distributional Characteristics And Stochastic Dominance versus Parametric Analysis In Testing Anomalies In The Emerging Market: Evidence From Jordan
}

Osamah Al-Khazali (E-mail: Kazali@aus.ac.ae), American University of Sharjah, United Arab Emirates

\begin{abstract}
Virtually all previous studies of seasonal variation in stock returns have used mean/variance analysis despite it being well documented that stock returns in developed and emerging markets are nonnormally distributed. This paper details the distributional characteristics of emerging Amman financial market returns. Further more, it uses stochastic dominance and parametric analyses to investigate the turn-of-the-year and the-week effects from 1978 to 2001. Results indicate that returns of Amman financial market exhibit substantial deviation from normality. And parametric analysis tests show there is January and week effects. However, stochastic dominance results indicate that January and week effects are not exist in the AFM. This implies that the results of parametric analysis are being driven by violations of parametric assumptions.
\end{abstract}

\subsection{Introduction}

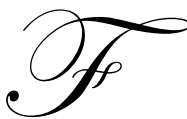

inancial markets around the world are now becoming more integrated as a result of liberalization programs in many developing countries. Large capital flows take place across international borders to take advantage of any perceived diversification benefits in these countries. Claessens (1995) notes that the total capital flows to all developing countries reached their highest level in 1993. For instance, foreign interest in the Jordanian stock market greatly increased with the Jordanian government's disclosure of its plan to liberalize the Jordanian stock market in the early 1990s. ${ }^{1}$ In fact, $42 \%$ of all investors in the Amman financial market (AFM) are considered to be foreign investors. The process of internationalization may hold many implications for both Jordanian and international investors.

The movement of capital funds into the developing countries has raised several policy questions. What benefits do investors get by investing in developing markets? If any, what rate of return can an investor realized on investments in developing countries? How well are the developing markets integrated with markets in industrial countries? Do stock markets in these countries price securities efficiently? What is the pattern of common stock returns in developing markets? The answers of these questions can be obtained through an analysis of these markets. Based on the forgoing, this study attempts to investigate the distribution and pattern of stock price movement in the emerging Amman financial market.

Previous studies have shown that the standard mean-variance analysis is somewhat problematical with respect to emerging markets, and therefore, emerging market returns cannot be completely characterized by these measures alone. Researchers have stated that there is significant skewness and kurtosis in these returns. ${ }^{2}$ Therefore, the results of previous studies, which examined anomalies, in emerging markets may be driven by violations of

\footnotetext{
${ }^{1}$ The Jordanian stock market is called the Amman financial market (AFM). It was established in 1976 and started its first day of business on January 1, 1978. The AFM emerged as one of the fastest-growing capital market in the Middle East.

${ }^{2}$ See Bekaert, Erb, Harvey, and Viskanat (1998) for more details.
} 
parametric assumptions. In order to avoid the possibility of these violations, this paper uses stochastic dominance analysis to investigate the January and the week effects in the Amman financial market. But first, it investigates the behavior and the distributional characteristics of stock returns.

Researchers have found systematic differences among returns for different months of the year and weeks of the month in stock returns in the U.S market as well as in the international markets. ${ }^{3}$ No fully satisfactory explanation has been provided for this apparent violation of the trading hypothesis. In the absence of a theoretically acceptable explanation for an observed phenomenon, the question of appropriateness of research methods arises. Virtually all previous studies have relied on parametric $t$ - and $F$-tests to document the January and the week effects in stock returns. While researchers recognize that these parametric tests are not strictly appropriate for assets with non-normally distributed returns, they assume that any deviation from normality is compensated for by the robustness of parametric methods. Bekaert et al. (1998) show that stock returns in developed and emerging markets are non-normally distributed. Therefore, this paper uses a stochastic dominance analysis to investigate the January and the week effects in the emerging Amman financial stock market. ${ }^{4}$ In fact, stochastic dominance is a useful tool for making comparisons among distributions without relying on parametric assumptions.

The remainder of this paper proceeds as follows: section II briefly discusses data description and analysis, section III discusses methodology and results of parametric analysis, section IV introduces stochastic dominance research methods and results, and section V summarizes.

\subsection{Data description and Analysis}

The data used in this paper is derived from three sources. The first source is the International Financial Corporation (IFC). The database includes monthly and weekly information on prices of stocks, return, market capitalization, price equity ratio, book market ratio, and stock price indexes for main emerging markets. The data available on the Amman financial market covers the period from January 1978 to December 2001 for monthly data, and from December 31, 1988 to December 31, 2001 for weekly data. The second source of data is based on the Amman financial publications. The AFM publishes a monthly statistical bulletin and annual report for companies trading in the market. The third source is the Statistical Bulletin published by the Central Bank of Jordan (CBJ). This monthly bulletin includes comprehensive statistical information about the Jordanian economy.

Table 1 presents the descriptive statistics of monthly and weekly stock returns from 1978 to 2001 and from 1988 to 2001, respectively. In the period of study, monthly and weekly mean returns of stocks are significantly different from zero. In addition, the monthly and weekly returns have a positive skewness and kurtosis. Jarque-Bera statistics for testing normality indicates that return distributions for monthly and weekly returns exhibit significant non-normality. Furthermore, descriptive statistics for each individual month and week returns are presented in Tables 2 and 3.

Table 2 shows that January, June, and December are the only months that have significantly positive mean returns among all months of the year. Furthermore, all months, except April and October, show positive skewness and all months show positive kurtosis. Table 3 reports that week 1 and 2 are the only weeks that have significantly positive mean returns. It also shows that all weeks have positive skewness and kurtosis.

Figure 1 shows the skewness of the emerging Amman financial market over the entire samples. The first bar of each pair represents the skewness in the 1980s, and the second bar represents the skewness in the 1990s. We split the sample between the 1980s and 1990s because capital market liberalizations in Jordanian stock market occurred in the early 1990s. In general, more countries have positive skewness in the 1990s than in the 1980s. Figure 2 replicates this

\footnotetext{
${ }^{3}$ Gultelkin and Gultelkin (1983), Lakonishok and Smidt (1984), and Jegadeesh (1991) have reported results that confirm a seasonality in the distribution of monthly stock returns across the world. Furthermore, for week effect see Ariel (1987), Jaffe and Westerfield (1989), Agrawal and Tandon (1994), and Penman (1987).

${ }^{4}$ Aggarwal and Leal (1993), Lee (1992), Bae and Kim (1996) and Claessens et al. (1995) report results that confirm the presence of equity return seasonalities in several emerging markets.
} 
analysis for excess kurtosis. The first bar of each pair represents the kurtosis in the 1980s, and the second bar represents the kurtosis in the 1990s. The figure shows positive kurtosis over the entire sample but more positive in the 1990s than in the 1980s.

Figures 3 and 4 detail the skewness and kurtosis for monthly returns and figures 5 and 6 detail skewness and kurtosis for weekly returns through time. The four figures show that skewness and kurtosis change through time and increase in 1990s.

Although we have a negative skewness in 1984, the excess kurtosis in AFM retains a similar pattern to the skewness. There is a distinct upward trend in skewness and kurtosis beginning in 1990. Even though the skewness and kurtosis had been increasing in the 1980s they were at a slower rate than in the 1990s. This is due to capital market liberalizations in the Amman financial market.

\subsection{Methodology and Results of Parametric Analysis}

In order to test for market seasonalities, January and week effects in the Amman financial market, this paper applies two parametric tests: analysis of variance (ANOVA) and the dummy variables regression model. The two tests are used to examine the hypothesis of equal mean values among months of the year and weeks of the month.

The hypothesis for testing the monthly returns pattern by using ANOVA is:

$$
\begin{array}{ll}
\mathrm{H}_{0}: & \mu_{1}=\mu_{2} \ldots \ldots \ldots \ldots \ldots \mu_{12}, \\
\mathrm{H}_{1}: & \text { not all } \mu_{\mathrm{j}} \text { are equal }
\end{array}
$$

We use the following dummy variable regression analysis to test the above hypothesis:

$$
R_{i, t}=\beta_{i, 1}+\sum_{k=2}^{12} \beta_{i, k} D_{k, t}+\varepsilon_{i, t}
$$

where $D_{k, t}$ is the seasonal dummy variable representing the calendar month $k$ and from k=2 (for February) to k=12 (for December). The intercept, $\beta_{i, 1}$ is the average stock return for the month of January and the coefficients for the monthly dummy variables, $\beta_{i, 2} \ldots \ldots, \beta_{i, 12}$, representing the average deviation of each month from the January return. Thus, if the monthly returns are equal, one expects the dummy variable coefficients to be statistically close to zero. Finally, the Wilcoxon-Mann-Whitney test was also applied to the data given its potential in determining ranking differences in pairwise observation.

For weekly effect, or turn of the month effect, we use the above methodology to test for weekly return pattern. The hypothesis for testing the weekly returns pattern by using ANOVA is:

$$
\begin{array}{ll}
\mathrm{H}_{0}: & \mu_{1}=\mu_{2} \ldots \ldots \ldots \ldots \mu_{4}, \\
\mathrm{H}_{1}: & \text { not all } \mu_{\mathrm{j}} \text { are equal }
\end{array}
$$

We use the following dummy variable regression analysis to test the above hypothesis:

$$
R_{i, t}=\beta_{i, 1}+\sum_{k=2}^{4} \beta_{i, k} D_{k, t}+\varepsilon_{i, t}
$$

The results of both monthly and weekly returns are provided in Table 4. The F values for ANOVA indicate that the amount of variation explained by the seasonal model is significant for monthly returns at $1 \%$ and significant 
for weekly returns at 5\%. This implies that there is seasonality in monthly and weekly returns in the Amman financial market.

In order to test the January and week effects, we apply the Wilcoxon-Mann Whitney pairwise test. This test is used to determine if the average January return is statistically different from each of the eleven other months. Also, it will be used to determine if the average of any week return is statistically different from the other three weeks. The results of this test are reported in Table 5.

The results in Table 5 indicate the presence of the January effect in the AFM. The Wilcoxon-MannWhitney test statistics are statistically significant for all months of the year except June. The implication of these results is that the average monthly returns for February through December are lower than the average January return except for June. These results are consistent with Rozeff and Kinney's (1976) findings in the U.S. market. Furthermore, the results in Table 5 indicate the presence of weekly effect in the AFM. The results show that the average weekly returns for week 2 through week 4 are lower than the average return of week 1 . In addition, we find that the average weekly returns for weeks 3 and 4 are lower than the average return of week 2. However, we find that no statistically significant differences occur between week 3 and 4 . We conclude that there is a high return in week 1 and 2 and lower returns in week 3 and 4. These findings are consistent with Ariel's (1987) findings in the U.S. market.

Table 6 reports the results of the application of dummy-variable regression to monthly returns. The coefficient $B_{1}$ is the measure of average returns in January while the other coefficients, $B_{2}$ through $B_{12}$, represent the difference between average returns in February through December and the average January return. In statistical sense, the average monthly returns in February through December are lower than January's average return except June. Thus, the dummy-variable regression results indicate the existence of the January effect in the Amman financial market.

Table 6 also reports the results of weekly returns. The coefficient $B_{1}$ is the measure of average returns in week 1 while the other coefficients, $B_{2}$ through $B_{4}$, represent the difference between average returns in week 2 through week 4 and the average return of week 1 . The results of dummy-variable regression indicate that week 1 returns are statistically significant and higher than week 2 through week 4 returns. This implies the existence of turn of the month effect in the Amman financial market.

The parametric analysis results support the turn of the year and the turn of the month effects in the Jordanian stock market. In the meantime, we have found that the distribution of stock returns in the AFM is characterized by non-normality. This non-normality in stock returns violates the assumptions of the parametric analysis. Therefore, the parametric tests results could be driven or caused by violations of parametric assumptions. Therefore, this paper implements a stochastic dominance analysis which does not require any assumptions about pattern of returns.

\subsection{Stochastic dominance methods and results}

Results of normality tests suggest that nonparametric methods, such as stochastic dominance, may lead to different conclusions if previous results are being driven by violations of parametric assumptions. Stochastic dominance requires no assumptions about the nature of underlying distributions and imposes few constraints on investor utility functions. Stochastic dominance tests are used to establish preferences among cumulative probability distributions.

There are three major types of stochastic dominance: first order (FSD), second order (SSD), and third order

(TSD). In general, stochastic dominance decision rules imply that more structure is imposed on investor preferences as one moves from FSD to TSD. Because of the lack of structure imposed by FSD, dominance of any one distribution under FSD is rare. The frequency which dominance is increase observed with SDD and TSD.

Stochastic dominance makes the following additional requirements on investors' utility functions. Investors must be non-satiated under FSD; non-satiated and risk averse under SSD; and non-satiated risk averse, 
with decreasing absolute risk aversion, under TSD. If there is stochastic dominance, then the expected utility of the investor is always higher under the dominant asset than under the dominated asset. Consequently, the dominated asset would never be chosen. Stochastic dominance results imply hierarchy. FSD implies SSD, which in turn, implies TSD. Hence, a finding that only TSD exists implies that SSD or FSD do not exist. The decision rules for these three levels of stochastic dominance with discrete distributions are developed in Porter, Wart, and Ferguson (1973) and are used here to determine whether any month or week in stock return distributions are dominant in the Amman financial market.

Table 7 provides results for the January returns over non-January returns. January returns generally exhibit dominance over non-January returns. January returns dominate two of the other 11 months (July and October) using FSD, dominate six of the 11 months (April, May, June, August, September, and November) using SSD, and dominate three of the 11 months (February, March, and October) using TSD. Therefore, January returns dominate non-January returns for all months using TSD. On the other hand, none of the other months dominate other months except April dominates October by TSD, November dominates October by TSD, and December dominates March and October by TSD. In order to have a strong January effect we should see that January return dominates all 11 months by FSD, because SSD and TSD capture small differences in return, and more structure is imposed on investor preferences as one moves from FSD to TSD. The results in Table 7 indicate that there is no seasonality or January effect in the AFM. These results contradict the results of parametric analysis which are provided in the previous section in this paper. The results of stochastic dominance analysis indicate that the results of the parametric analysis are biased and may be driven by violations of the parametric assumptions.

Table 8 reports results for the weekly dominance. Week 1 returns dominate week 3 and 4 returns using FSD but it does not dominate week 2. On the other hand, the returns of week 4 are dominated by week 2 returns using TSD. However, week 3 and 4 returns do not dominate each other nor dominate week 1 or 2 returns. The results in Table 8 provide weak evidence for week effect. But one can say that week 1 provides higher returns than week 3 and 4 . And the first half of the month provides higher returns than the second half of the month. These results contradict the parametric analysis results in this study.

In summary, due to the contradiction between the parametric analysis results and stochastic dominance analysis results, one can conclude that the results of the parametric analysis could be driven by violations of parametric assumptions. Therefore, parametric analysis should not be used when there are any violations for the assumptions. These results were expected because of the skewness and kurtosis in returns over time in the AFM. Finally, the stochastic dominance provides stronger results than the parametric analysis.

\subsection{Summary}

The recent literature on emerging equity markets indicates that returns of these markets exhibit substantial deviations from normality. This study details these departures from normality in the Jordanian equity market. Furthermore, it investigates anomalies in the AFM. We applied stochastic dominance and parametric analyses to test for seasonalities.

For parametric analysis, we used ANOVA and the dummy-variable regression model. The two methods show that there is January and week effects in the AFM over the period of study. The Wilcoxon-Mann-Whitney test was also applied to determine ranking differences in pairwise observation. It shows that the month of January provides a higher return than all the months of the year except the month of June. In addition, it reports that returns of week 1 are higher than the returns of other weeks. According to the parametric analysis there is evidence to support the turn of the year and the week effects.

However, the stochastic dominance analysis provides the opposite results. It shows that there is no seasonality or January effect in the AFM. In order to have a strong January effect we should see that January return dominates all 11 months by FSD, because SSD and TSD capture small differences in return, and more structure is imposed on investor preferences as one moves from FSD to TSD. 
Furthermore, the results of stochastic dominance analysis report weak evidence for week effect. But one can say that week 1 provides higher returns than week 3 and 4 . And the first half of the month provides higher returns than the second half of the month. These results contradict the parametric analysis results in this study.

In summary, due to the contradiction between the results of parametric and stochastic dominance analyses, one can conclude that the results of the parametric analysis could be driven by violations of parametric assumptions. Therefore, parametric analysis should not be used when there is any violation of the assumptions. These results were expected because of the skewness and kurtosis in returns over time in the AFM. Finally, the stochastic dominance provides stronger results than the parametric analysis.

\section{References}

1. Aggarwal, R. and R. Leal, 1993, Integration and Anomalies in the emerging markets of Asia and Latin America, Working paper, Georgetown University, Washington, D.C.,

2. Agrawal, A. and K. Tandon ,1994, Anomalies or illusions? Evidence from stock market in eighteen countries, Journal of International Money and Finance, 13, 83-106.

3. Ariel, R. A., 1987, A monthly effect in stock returns, Journal of Financial Economics, 18, 161-174.

4. Bae, C. and D. Kim ,1996, A Revisit to return seasonality and the tax selling hypothesis in the Korean market, Global Business and Finance Review, 1, 39-46.

5. Bekaert, G, Claud B., Campbell R., and Viskanata, T, 1998, Distributional characteristics of emerging market returns and asset allocation, Journal of Portfolio

6. Management, 102-116.

7. Claessens, S., 1995, The emergence of equity investment in developing countries: Overview, The World Bank Economic Review, 9, 1-17.

8. Claessens, S., S Dasgupta and J. Glen, 1995, Return behavior in emerging stock markets, The World Bank Economic Review, 9, 131-151.

9. Gultelkin, M and N. Gultelkin, 1983, Stock market seasonality, Journal of Financial Economics, 12, 469481.

10. Jaffee J and R. Westerfield ,1989, Is there a monthly effect in stock market returns? Evidence from foreign countries, Journal of Banking and Finance, 13, 237-244.

11. Jagadeesh, N., 1991, Seasonality in stock price mean reversion: Evidence from the U.S. and the U.K., Journal of Finance, 46, 1427-1444.

12. Lakonishok, J. and S. Smidt, 1988, Are seasonal anomalies real? ninety-year perspective, Review of Financial Studies, 1, 403-425.

13. Lakonishok, J. and S. Smidt, 1984, Volume and turn-of-the-year behavior, Journal of Financial Economics, 13, 883-889.

14. Lee, Insup, 1992, Stock market seasonality: Some evidence from the Pacific-Basin countries, Journal of Business Finance \& Accounting, 19, 199-210.

15. Penman, Stephen, 1987, The distribution of earning news over time and seasonalities in aggregate stock returns, Journal of Financial Economics, 18,199-228.

16. Porter, R. B., J. R. Wart and D. L. Ferguson, 1973, Efficient algorithms for conduction stochastic dominance tests on large numbers of portfolios, Journal of Financial and Quantitative Analysis, 8, 71-81.

17. Rozeff, M. and W. Kinney,1976, Capital market seasonality: the case of stock returns, Journal of Financial Economics, 3, 379-402.

Figure 1: Skewness in the 1980s and 1990s
Figure 2: Excess kurtosis in the 1980s and 1990s 


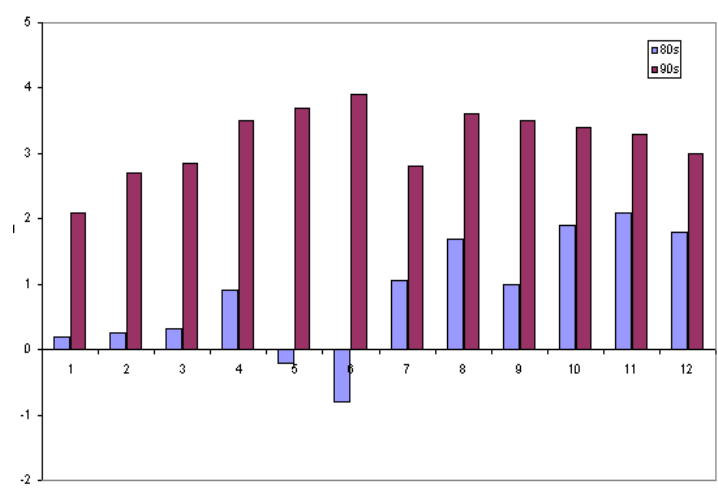

Figure 3: Skewness in monthly returns through time

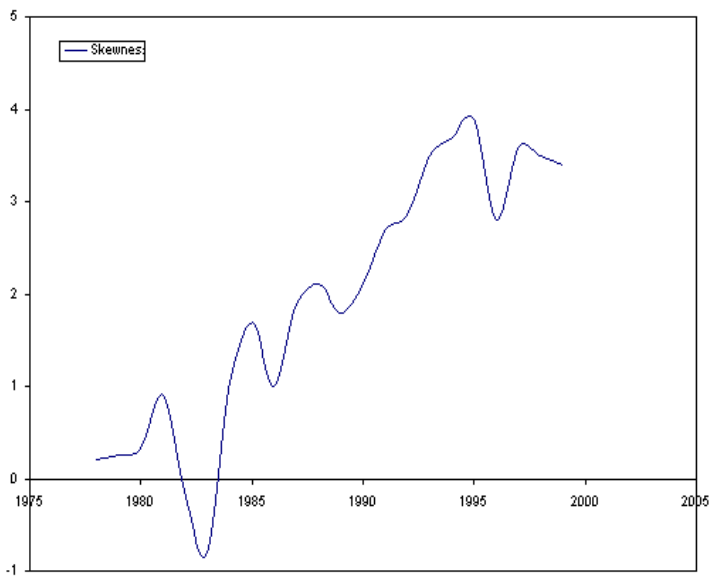

Figure 5: Skewness in weekly returns through time

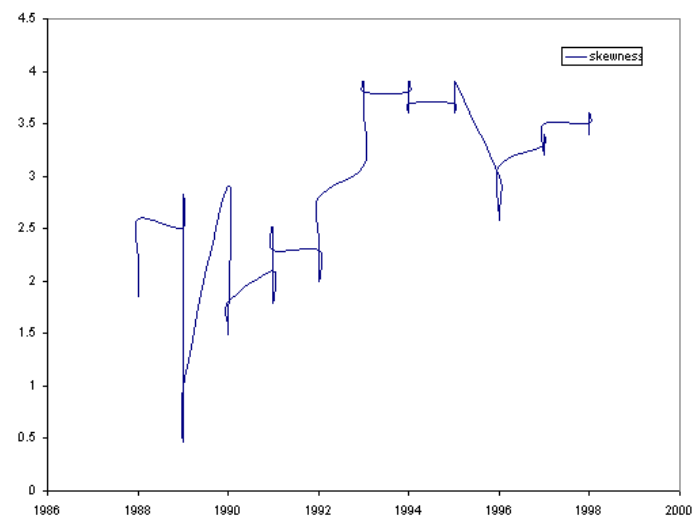

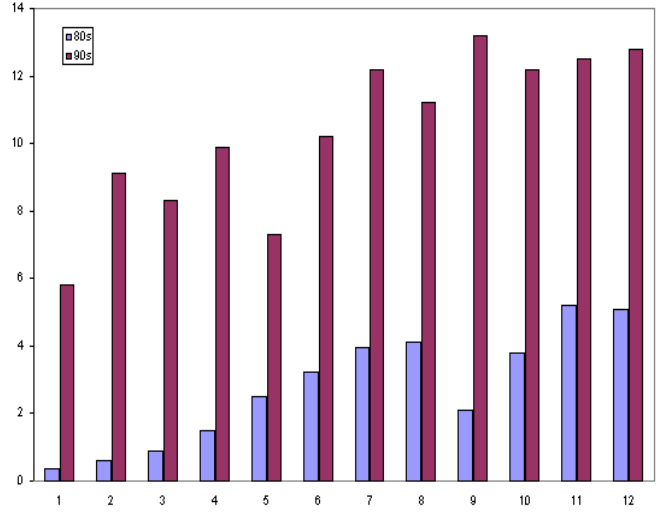

Figure 4: Excess kurtosis in monthly returns through time

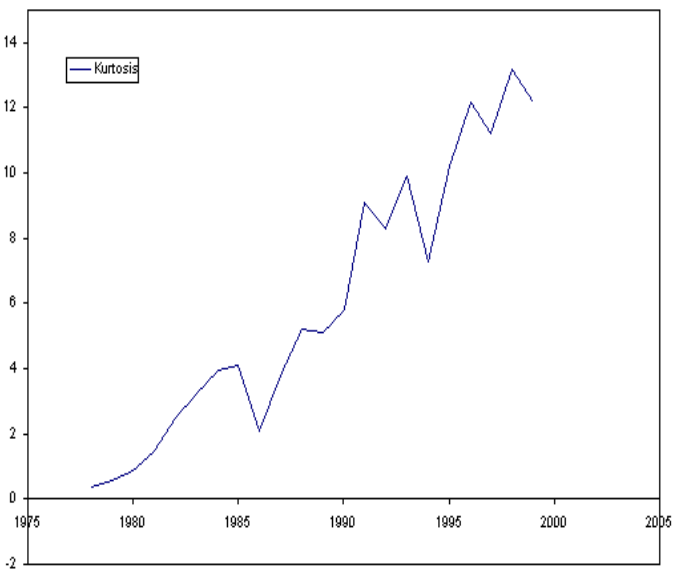

Figure 6: Excess kurtosis in weekly returns through time

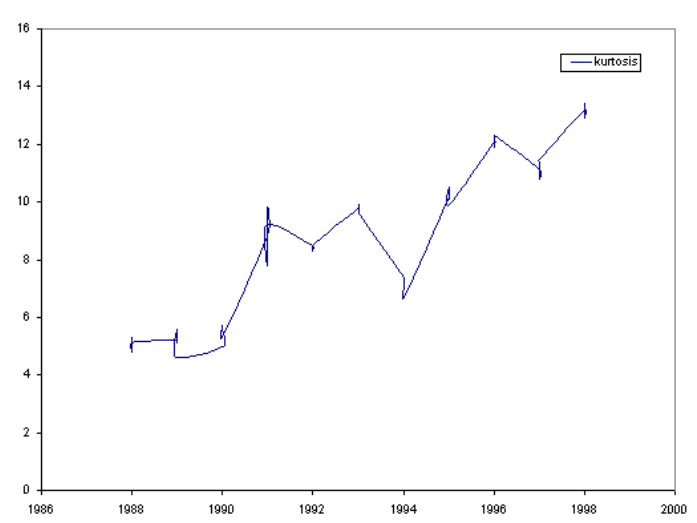


Table 1: Descriptive statistics of monthly returns from 1978-2001 and 1988-2001 of weekly returns.

\begin{tabular}{lllllll}
\hline Returns & Mean & S.D & $t$ statistics & Skewness & Kurtosis & Jarque-Bera \\
\hline Monthly & 6.23 & 24 & $3.54^{* *}$ & 0.54 & 11.23 & $1342^{* * * *}$ \\
Weekly & 3.21 & 18 & $1.61^{*}$ & 0.62 & 14.65 & $2546^{* * * *}$ \\
\hline
\end{tabular}

Notes:'***', ‘**', ‘*' indicate statistical significance at the $1 \%, 5 \%$, and $10 \%$ levels, respectively.

Table 2: Descriptive statistics of stock returns for each calendar month from 1978 to 2001

\begin{tabular}{lllllr} 
Month & Mean & S.D & $t$ statistics & Skewness & Kurtosis \\
\hline Jan. & 6.21 & 3.21 & $5.76^{* * * *}$ & 2.32 & 13.21 \\
Feb. & 1.56 & 2.51 & 0.67 & 1.65 & 8.12 \\
Mar. & 0.76 & 6.87 & 0.98 & 2.43 & 10.21 \\
Apr. & -0.15 & 2.65 & -0.25 & -2.14 & 4.76 \\
May & 0.76 & 3.76 & 0.74 & 0.98 & 12.11 \\
Jun. & 1.21 & 2.98 & $2.76^{* *}$ & 2.54 & 6.32 \\
Jul. & 0.54 & 3.65 & 0.97 & 1.32 & 5.23 \\
Aug. & 0.34 & 2.87 & 0.87 & 0.32 & 3.21 \\
Sep. & 0.16 & 3.97 & 0.74 & 0.15 & 1.76 \\
Oct. & -0.07 & 2.45 & -0.65 & -0.28 & 3.65 \\
Nov. & 0.25 & 2.98 & 0.52 & 0.76 & 1.54 \\
Dec. & 0.82 & 3.45 & $1.66^{*}$ & 1.32 & 3.65 \\
\hline
\end{tabular}

Notes:'***', ‘**', ‘*' indicate statistical significance at the $1 \%, 5 \%$, and $10 \%$ levels, respectively.

Table 3: Descriptive statistics of stock returns for each calendar week from 1988 to 2001

\begin{tabular}{llllll} 
Returns & Mean & S.D & $t$ statistics & Skewness & Kurtosis \\
\hline Week 1 & 4.21 & 6.43 & $5.21^{* * * *}$ & 0.87 & 9.34 \\
Week 2 & 3.21 & 5.45 & $2.98^{* * *}$ & 1.21 & 5.32 \\
Week 3 & 2.98 & 4.34 & 0.76 & 0.34 & 8.98 \\
Week 4 & 2.34 & 4.01 & 0.34 & 0.76 & 6.87 \\
\hline
\end{tabular}

Notes: ${ }^{* * *}$, '**', '*' indicate statistical significance at the $1 \%, 5 \%$, and $10 \%$ levels, respectively.

Table 4: Test of equal mean returns in each calendar month and week using ANOVA

\begin{tabular}{lll} 
Stock & F value & $\mathrm{P}(\mathrm{F})$ \\
\hline Monthly & $4.12^{* * *}$ & 0.0001 \\
Weekly & $2.65^{*}$ & 0.0430 \\
\hline Notes:'***', '**', '*' indicate statistical significance at the $1 \%, 5 \%$, and $10 \%$ levels, respectively.
\end{tabular}

Table 5: Wilcoxon-Mann-Whitney Test for January and week effect (p-value in parenthesis)

\begin{tabular}{llll} 
Return Pair & Value & Return Pair & Value \\
\hline JAN/FEB & $-1.81(0.071)^{*}$ & week1/week2 & $-1.65(0.090)^{*}$ \\
JAN/MAR & $-1.76(0.078)^{*}$ & week1/week3 & $-2.25(0.021)^{* *}$ \\
JAN/APR & $-2.15(0.034)^{* *}$ & week1/week4 & $-2.37(0.018)^{* *}$ \\
JAN/MAY & $-2.20(0.028)^{* *}$ & week2/week3 & $-1.87(0.063)^{*}$ \\
JAN/JUN & $-0.65(0.350)$ & week2/week4 & $-1.96(0.050)^{* *}$ \\
JAN/JUL & $-2.40(0.016)^{* *}$ & week3/week4 & $-0.56(0.450)$ \\
JAN/AUG & $-1.96(0.050)^{* *}$ & & \\
JAN/SEP & $-1.72(0.084)^{*}$ & & \\
JAN/OCT & $-1.85(0.068)^{*}$ & & \\
JAN/NOV & $-2.44(0.012)^{* *}$ & & \\
JAN/DEC & $-1.87(0.065)^{*}$ & & \\
& & & \\
\hline
\end{tabular}

Notes:'***', ‘**’, ‘*’ indicate statistical significance at the $1 \%, 5 \%$, and $10 \%$ levels, respectively. 
Table 6: Dummy-Variable Regression Analysis of January and weekly effects.

\begin{tabular}{llll}
$\begin{array}{l}\text { Regression } \\
\text { Coefficient }\end{array}$ & Value & $\begin{array}{l}\text { Regression } \\
\text { Coefficient }\end{array}$ & Value \\
\hline B1 & $-11.23(0.090)^{*}$ & B1 & $-13.12(0.053)^{*}$ \\
B2 & $-13.11(0.05)^{* *}$ & B2 & $-11.23(0.09)^{*}$ \\
B3 & $-11.45(0.078)^{*}$ & B3 & $-13.65(0.056)^{*}$ \\
B4 & $-12.34(0.072)^{*}$ & B4 & $-13.78(0.051)^{*}$ \\
B5 & $-11.56(0.066)^{*}$ & & \\
B6 & $0.76(0.91)$ & & \\
B7 & $-12.34(0.084)^{*}$ & & \\
B8 & $-10.88(0.096)^{*}$ & & \\
B9 & $-11.54(0.064)^{*}$ & & \\
B10 & $-12.7(0.075)^{*}$ & & \\
B11 & $-11.32(0.071)^{*}$ & & \\
B12 & $-12.76(0.081)^{*}$ & & \\
& & & \\
\hline
\end{tabular}

Notes:'***', '**', '*' indicate statistical significance at the $1 \%, 5 \%$, and $10 \%$ levels, respectively.

Table 7: Stochastic dominance comparisons for monthly returns among all months from 1978-2001.

\begin{tabular}{lcllllllllll} 
Month & FEB & MAR & APR & MAY & JUN & JUL & AUG & SEP & OCT & NOV & DEC \\
\hline JAN & TSD & TSD & SSD & SSD & SSD & FSD & SSD & SSD & FSD & SSD & TSD \\
FEB & - & NSD & NSD & NSD & NSD & NSD & NSD & NSD & NSD & NSD & NSD \\
MAR & NSD & - & NSD & NSD & NSD & NSD & TSD & NSD & NSD & NSD & NSD \\
APR & NSD & NSD & - & NSD & NSD & NSD & NSD & NSD & TSD & NSD & NSD \\
MAY & NSD & NSD & - & - & NSD & NSD & NSD & NSD & NSD & NSD & NSD \\
JUN & NSD & NSD & - & NSD & - & NSD & NSD & NSD & NSD & NSD & NSD \\
JUL & NSD & NSD & - & NSD & NSD & - & NSD & NSD & NSD & NSD & NSD \\
AUG & NSD & NSD & - & NSD & NSD & NSD & - & NSD & NSD & NSD & NSD \\
SEP & NSD & NSD & - & NSD & NSD & NSD & NSD & - & NSD & NSD & NSD \\
OCT & NSD & NSD & - & NSD & NSD & NSD & NSD & NSD & - & NSD & NSD \\
NOV & NSD & NSD & - & NSD & NSD & NSD & NSD & NSD & TSD & - & NSD \\
DEC & NSD & TSD & - & NSD & NSD & NSD & NSD & NSD & TSD & NSD & - \\
& & & & & & & & & & &
\end{tabular}

The notation FSD denotes first-order stochastic dominance, SSD denotes second-order, and TSD denotes third-order, respectively. An entry in the table means that the monthly returns on the left dominate monthly returns indicated across the top.

Table 8: Stochastic dominance comparisons for weekly returns among all weeks from 1988-2001.

\begin{tabular}{|c|c|c|c|c|}
\hline Week & 1 & 2 & 3 & 4 \\
\hline 1 & - & NSD & FSD & FSD \\
\hline 2 & NSD & - & NSD & TSD \\
\hline 3 & NSD & NSD & - & NSD \\
\hline$\underline{4}$ & NSD & NSD & NSD & - \\
\hline
\end{tabular}


Notes 